\begin{tabular}{ll|l} 
Case Reports in & \multicolumn{2}{c}{ Case Rep Gastroenterol 2013;7:56-62 } \\
\cline { 2 - 3 } Gastroenterology & $\begin{array}{l}\text { DOI: } 10.1159 / 000346570 \\
\text { Published online: February 25, 2013 }\end{array}$ & $\begin{array}{l}\text { ○ 2013 S. Karger AG, Basel } \\
\text { www.karger.com/crg }\end{array}$ \\
\hline & $\begin{array}{l}\text { This is an Open Access article licensed under the terms of the Creative Commons Attribution- } \\
\text { NonCommercial-NoDerivs 3.0 License (www.karger.com/OA-license), applicable to the } \\
\text { online version of the article only. Distribution for non-commercial purposes only. }\end{array}$
\end{tabular}

\title{
Successful Endoscopic Therapy of Traumatic Bile Leaks
}

\author{
Matthew P. Spinn ${ }^{a}$ Mihir K. Patel ${ }^{c} \quad$ Bryan A. Cotton $^{b} \quad$ Frank J. Lukens $^{a, c}$ \\ ${ }^{a}$ Division of Gastroenterology and ${ }^{b}$ Department of Surgery, University of Texas \\ Health Science Center, Houston, Tex., and 'Division of Gastroenterology, Mayo Clinic, \\ Jacksonville, Fla., USA
}

\section{Key Words}

Bile leak · Trauma · Endoscopy · Bile injury · Hepatic injury · Endoscopic retrograde cholangiopancreatography $\cdot \mathrm{ERCP}$

\begin{abstract}
Traumatic bile leaks often result in high morbidity and prolonged hospital stay that requires multimodality management. Data on endoscopic management of traumatic bile leaks are scarce. Our study objective was to evaluate the efficacy of the endoscopic management of a traumatic bile leak. We performed a retrospective case review of patients who were referred for endoscopic retrograde cholangiopancreatography (ERCP) after traumatic bile duct injury secondary to blunt (motor vehicle accident) or penetrating (gunshot) trauma for management of bile leaks at our tertiary academic referral center. Fourteen patients underwent ERCP for the management of a traumatic bile leak over a 5 -year period. The etiology included blunt trauma from motor vehicle accident in 8 patients, motorcycle accident in 3 patients and penetrating injury from a gunshot wound in 3 patients. Liver injuries were grade III in 1 patient, grade IV in 10 patients, and grade $\mathrm{V}$ in 3 patients. All patients were treated by biliary stent placement, and the outcome was successful in 14 of 14 cases (100\%). The mean duration of follow-up was 85.6 days (range 54-175 days). There were no ERCP-related complications. In our case review, endoscopic management with endobiliary stent placement was found to be successful and resulted in resolution of the bile leak in all 14 patients. Based on our study results, ERCP should be considered as first-line therapy in the management of traumatic bile leaks.
\end{abstract}


Spinn et al.: Successful Endoscopic Therapy of Traumatic Bile Leaks

\section{Introduction}

The main cause of noniatrogenic injury to the biliary system is trauma. Bile leaks can result from penetrating injury, such as gunshot (GSW) or knife wounds, or from blunt trauma, such as motor vehicle (MVA) or motorcycle accidents (MCA). The incidence of bile leaks following hepatobiliary trauma ranges from 0.5 to $21 \%$ depending on the criteria and methods used to diagnose the bile leak [1-3]. Following blunt or penetrating abdominal trauma, there can be significant damage to the biliary tract with severe injuries (grades III$\mathrm{VI}$ ) leading to an intrahepatic biloma, intraperitoneal leakage of bile, hemobilia and bilhemia, and intra-abdominal abscess [1]. There is no consensus on the treatment of traumatic bile leaks and decisions are often based on extent and mechanisms of injury, associated organ injuries and local expertise.

Regardless of the etiology, bile leaks can be a considerable cause of morbidity in afflicted patients. Unstable patients, as well as those with a penetrating injury, require laparotomy in conjunction with less invasive techniques. Hemodynamically stable patients with blunt hepatic trauma can be managed nonoperatively which has become the treatment of choice over the past two decades [4]. In earlier years, the main treatment options were surgical. However, the treatment of bile leaks has evolved with improvements in technology and procedural techniques.

The management of surgical bile leaks with therapeutic endoscopic retrograde cholangiopancreatography (ERCP) is well-established $[5,6]$. However, the diagnosis of traumatic bile leaks can often be delayed and difficult. It has been suggested that posttraumatic bile leaks require more therapeutic procedures, patients have longer hospital courses, and higher hospital charges [7]. ERCP has been found to be a useful tool for the diagnosis and treatment of posttraumatic bile leaks, but data on outcome after therapeutic ERCP for traumatic bile leaks is limited $[1,3,8,9]$. Several case reports and a case series in the surgical literature report that ERCP can be useful in the management of traumatic bile leaks [8]. A variety of endoscopic techniques have been used to manage bile leaks. These include biliary sphincterotomy alone, biliary stenting with or without sphincterotomy, and nasobiliary drainage with or without sphincterotomy. These methods share the common goal of decreasing or eliminating the pressure gradient between the bile duct and duodenum, allowing preferential flow of bile from the duct into the duodenum instead of bile exiting the leak site. The absence of ongoing bile flow through the leak site allows the defect to heal $[1,8]$.

We conducted a retrospective case review to evaluate the role of ERCP in the management of patients who present with a bile leak after blunt or penetrating abdominal trauma.

\section{Patients and Methods}

The prospectively recorded endoscopy database at the University of Texas Health Science Center, Houston, Tex., USA, was reviewed to identify all patients who underwent ERCP for the management of traumatic bile leaks between January 2004 and March 2009. All patients who developed a posttraumatic bile leak were included, regardless of the mechanism of injury (blunt vs. penetrating) or the initial method of management (operative vs. nonoperative).

All patients were admitted to the trauma service and were initially managed in the surgical intensive care unit. Twelve of 14 patients underwent surgical exploration with or without percutaneous drain placement. Two of the 14 patients were initially managed conservatively with 1 of these 2 patients eventually undergoing interventional radiology 
Spinn et al.: Successful Endoscopic Therapy of Traumatic Bile Leaks

computed tomographic-assisted aspiration of biloma and drain placement. A bile leak was suspected when there was persistent drainage of bile via the surgical wound or through an intra-abdominal drain placed at surgery, after percutaneous drainage of a perihepatic fluid collection, or a positive hepatoiminodiacetic acid scan or when a computed tomography (CT) scan revealed a subhepatic fluid collection.

ERCP was performed with standard therapeutic duodenoscopes (Olympus TJF-100/ 130/140/160; Olympus America Corporation, Inc., Melville, N.Y., USA) by one attending endoscopist within $48 \mathrm{~h}$ of referral. Patients underwent ERCP in the endoscopy unit with the assistance of anesthesia, using a combination of diprivan, meperidine, and midazolam or in the operating room if patient remained intubated. Once a bile leak was demonstrated on cholangiogram, a 7.0-, 8.5- or 10-F transpapillary biliary stent (Cook Endoscopy, WinstonSalem, N.C., USA) was placed. A biliary sphincterotomy was performed routinely in all patients. After the ERCP, surgically or percutaneously placed drains were removed after there was decreased or absent output from the drains. A repeat ERCP was performed 4-16 weeks later to evaluate for resolution of a bile leak. The time interval between ERCPs varied among patients because most of them had other associated injuries, were critically ill, and required other interventions. On repeat ERCP, all bile leaks had resolved and the previously placed endobiliary stent was removed. The patients were monitored daily after ERCP for $48 \mathrm{~h}$ to asses for any complications and again in clinic 1-2 weeks after discharge.

Endoscopic therapy was considered successful if the bile leak had resolved at the time of repeat ERCP. Failure of endoscopic therapy was defined as persistence of a bile leak at follow-up ERCP, persistence of biliary drainage through the percutaneous drain or persistence of biloma on CT that necessitated additional interventions to manage the bile leak.

To assess the long-term outcome, follow-up data were obtained by telephone contact with the patients, who were questioned specifically about any evaluation or treatment of a recurrent bile leak, as well as complications, subsequent to their last endoscopic treatment. All patients or their immediate relatives provided informed consent for the procedure.

\section{Results}

A total of 14 patients ( 9 men, age range 16-61 years; 5 women, age range 11-45 years), between January 2004 and March 2009, underwent ERCP for a bile leak secondary to traumatic injury to the abdomen. Eleven cases were because of blunt trauma: MVA in 8, and MCA in 3; the remaining 3 were because of penetrating trauma from a GSW. Injuries were graded according to predefined criteria [10] and were grade III $(<3 \mathrm{~cm}$ parenchymal laceration) in 1 patient, grade IV (25-75\% parenchymal disruption) in 10 patients, and grade $\mathrm{V}$ ( $>75 \%$ parenchymal disruption with or without involvement of major hepatic vasculature) in 3 patients. ERCP was successful in all patients. A biliary sphincterotomy was performed in all patients. Bile leaks were located in the common bile duct (CBD) in 1 patient, right ductal system in 8 patients, and in the left ductal system in 5. Twelve of the 14 patients underwent surgery for other associated injuries. Other associated injuries included lacerations to the spleen, diaphragm, kidney or major abdominal vessels, and hemothorax. Details on patient demographics and the nature of bile duct injury with location, interventions, and outcomes are shown in table 1 . There were no documented post-ERCP complications.

Of the 8 patients with MVA, 6 were initially managed with surgery. Two patients were managed conservatively until bile leak was suspected based on CT scan findings. One of these 2 patients subsequently underwent CT-guided biloma drainage and percutaneous drain placement. All 8 patients eventually underwent ERCP with a bile leak found in the right 
Spinn et al.: Successful Endoscopic Therapy of Traumatic Bile Leaks

hepatic system in 4 and in the left hepatic system in 3. One patient had a bile leak in the CBD. All patients had an endobiliary stent placed. Of the 3 patients with MCA, all were initially managed with surgery with subsequent ERCP with endobiliary stent placement. Follow-up ERCP done in all patients with blunt trauma revealed resolution of the bile leak and the stent was removed.

Three patients had a penetrating injury (grade V in all 3) from a GSW and required emergent surgery. All 3 patients underwent ERCP because of continued bilious output from the surgically placed drain. Two of the 3 patients were found to have a bile leak from the left ductal system on cholangiogram, the third patient was found to have a bile leak from the right ductal system. All 3 patients had endobiliary stents placed. Of note, 2 of the 3 patients had delayed presentation of the bile leak. One of the 2 patients developed bilious output from the surgically placed drain on postoperative day 11 . The other patient developed fever and pain on postoperative day 18 and CT scan revealed a perihepatic fluid collection which prompted the referral for ERCP. At follow-up ERCP, all 3 patients had resolution of the bile leak and the endobiliary stents were removed.

\section{Discussion}

This study showed that ERCP with sphincterotomy and endobiliary stent placement is effective in the treatment of patients with major bile duct damage after hepatobiliary trauma. In our series, the resolution of a bile leak was seen in $100 \%$ of patients who underwent endobiliary stent placement and sphincterotomy. This data is supported by a recent study reported by Lubezky et al. [8], where ERCP with biliary sphincterotomy and stent placement was found to be effective in all 11 patients who developed a traumatic bile leak. Also, in a study by Bridges et al. [9], resolution of a traumatic bile leak was seen in $90 \%$ of patients who underwent endobiliary stent placement.

Biliary ductal injuries may not be seen on initial imaging or laparotomy and can therefore have an insidious presentation. The biliary injuries that result from hepatic trauma may be simple bile leaks into the lacerated liver, peritoneal cavity or pleural cavity or may result in biliary-vascular fistulas. Bile leaks usually present several days after the initial trauma, with the patient complaining of abdominal pain, increasing abdominal distention, and ascites. In the setting of penetrating abdominal trauma such as GSW, presentation of bile leak can be delayed up to two weeks as was reported previously [11].

The biliary injury can be intrahepatic, extrahepatic or both. In our series, 13 of 14 patients had injuries to the intrahepatic ductal system. Nine of the 14 cases had involvement of the right intrahepatic ductal system. The other 4 cases involved the left intrahepatic ductal system and 1 involved the CBD. In previous series, the right intrahepatic ducts were the predominant sites of bile leaks following abdominal trauma $[1,9,12]$. Whether or not the location of the bile leak can predict treatment outcome is still unclear and cannot be elicited from our study or others.

Hepatobiliary injuries can be complex and management remains a challenge to surgeons. Surgery has been the conventional treatment for posttraumatic bile leaks but can be difficult to perform due to a combination of adhesions, inflammation, damaged liver parenchyma or the patient being a poor surgical risk. The most important factors that influence survival in these patients are the associated injuries and the nature and the extent of liver injury [13]. It has been shown that liver-related complications appear to be less frequent in patients managed without surgery than in those managed surgically [8-10]. Nonoperative management of bile duct injury is effective with success rate ranging from 90 to $94 \%$. In our 
series, the resolution of bile leak was seen in all patients following endoscopic treatment. The success rate of therapeutic endoscopic intervention ranges from 90 to $100 \%[1,8,9,12]$. Sugiyama et al. [3] reported healing of bile leaks in 5 of 6 patients after therapeutic ERCP. In a series by Bajaj et al. [14], therapeutic ERCP was successful in 8 of 9 (89\%) patients for managing posttraumatic bile leaks. Bridges et al. [9] reported healing of bile leaks in 9 of 10 $(90 \%)$ patients after biliary stenting. Hence, an ERCP is both of diagnostic and therapeutic benefit in these patients.

In the present series, resolution of bile leak was documented on repeat ERCP which was anywhere from 4 to 16 weeks after initial ERCP. Sharma et al. [12] documented resolution of bile leak after 8.5 days (range 3-30 days) of endoscopic interventions. In a series by Singh et al. [1], bile leaks closed in 15.76 days in patients who had undergone sphincterotomy, and in 12.14 days in patients without sphincterotomy. Lubezky et al. [8] reported resolution of bile leaks in 6-7 days (range 5-10 days) after ERCP. Sugiyama et al. [3] reported healing of bile leaks after 1-7 days of ERCP. Bajaj et al. [14] reported time to resolution of bile leak after ERCP as 7.4 days (range $2-17$ days).

We routinely perform biliary sphincterotomy and endobiliary stent placement for the management of a bile leak. There were no complications related to endoscopic sphincterotomy. There are, however, several studies that clearly demonstrate the efficacy of biliary stent placement alone in this cohort of patients [3]. Other series support our combined approach of endoscopic sphincterotomy and stenting for management of bile leaks following hepatic trauma $[8,9,12]$. In major leaks it is unlikely that sphincterotomy alone can seal the leak [15].

The ideal length of time for stenting is not known. It has varied from 3 to 8 weeks in previously published reports [1]. We removed the stents after an interval of 4-16 weeks.

Follow-up in our patients ranged from 54 to 175 days (mean of 85.6 days). None of our patients showed evidence of post-ERCP complications. In a study by Sugiyama et al. [3] on long-term follow-up, there were no late complications after endoscopic treatment. In the series by Sharma et al. [12], after a mean follow-up of 33 months, there were no complications and all the patients remained asymptomatic.

The limitations of this study include the retrospective case series design as well as the small number of subjects included in the series. This particular cohort is small in the general population, and thus these procedures are rarely undertaken. However, our series of 14 subjects is more than previously published series. As was the case with previously published case series, the management of bile leaks was not standardized. The follow-up was also short compared to other studies, and thus some long-term complications from ERCP could have occurred.

In summary, this study demonstrated the efficacy of ERCP with sphincterotomy and endobiliary stent placement in the management of patients with extensive traumatic hepatic injury with intrahepatic bile leaks. The severity of an injury and the site of a bile leak do not preclude endotherapy as a management option in these patients. The results of our series and those of previously published series suggest that ERCP should be considered as a firstline therapy for traumatic bile leaks.

\section{Disclosure Statement}

Drs. Matthew P. Spinn and Frank J. Lukens have no conflicts of interest or financial ties to disclose. 


\begin{tabular}{l|l}
\hline \multicolumn{2}{l}{ Case Rep Gastroenterol 2013;7:56-62 } \\
\hline DOI: $\underline{10.1159 / 000346570}$ & $\begin{array}{l}\text { C 2013 S. Karger AG, Basel } \\
\text { www.karger.com/crg }\end{array}$ \\
\hline
\end{tabular}

Spinn et al.: Successful Endoscopic Therapy of Traumatic Bile Leaks

\section{References}

1 Singh V, Narasimhan KL, Verma GR, Singh G: Endoscopic management of traumatic hepatobiliary injuries. J Gastroenterol Hepatol 2007;22:1205-1209.

-2 Pachter HL, Knudson MM, Esrig B, Ross S, Hoyt D, Cogbill T, Sherman H, Scalea T, Harrison P, Shackford S, Ochsner MG, Mucha P, Hofstetter SR, Guth A, Coffey S, Kataju S, Marburger R, Garcia J, Savage B, Henry S, Lippold, D, Trevesani G, Steinig J: Status of nonoperative management of blunt hepatic injuries in 1995: a multicenter experience with 404 patients. J Trauma 1996;40:31-38.

-3 Sugiyama M, Atomi Y, Matsuoka T, Yamaguchi Y: Endoscopic biliary stenting for treatment of persistent biliary fistula after blunt hepatic injury. Gastrointest Endosc 2000;51:42-44.

4 Cogbill TH, Moore EE, Jurkovich GJ, Feliciano DV, Morris JA, Mucha P: Severe hepatic trauma: a multicenter experience with 1,335 liver injuries. J Trauma 1988;28:1422-1438.

5 Johnston TD, Gates R, Reddy KS, Nickl NJ, Ranjan D: Nonoperative management of bile leaks following liver transplantation. Clin Transplant 2000;14:365-369.

-6 Kaffes AJ, Hourigan L, De Luca N, Byth K, Williams SJ, Bourke MJ: Impact of endoscopic intervention in 100 patients with suspected postcholecystectomy bile leak. Gastrointest Endosc 2005;61:269-275.

7 Vassiliu P, Toutouzas KG, Velmahos GC: A prospective study of posttraumatic biliary and pancreatic fistuli. The role of expectant management. Injury 2004;35:223-227.

-8 Lubezky N, Konikoff FM, Rosin D, Carmon E, Kluger Y, Ben-Haim M: Endoscopic sphincterotomy and temporary internal stenting for bile leaks following complex hepatic trauma. Br J Surg 2006;93:78-81.

-9 Bridges A, Wilcox CM, Varadarajulu S: Endoscopic management of traumatic bile leaks. Gastrointest Endosc 2007;65:1081-1085.

10 Moore EE, Cogbill TH, Jurkovich MD, Shackford SR, Malangoni MA, Champion HR: Organ injury scaling: spleen and liver (1994 revision). J Trauma 1995;38:323.

11 Spinn MP, Adler DG: Successful endoscopic therapy of intrahepatic bile leaks following hepatic gunshot injury: report of two cases. Endoscopy 2006;38:859.

12 Sharma BC, Mishra BC, Kumar R, Sarin SK: Endoscopic management of bile leaks after blunt abdominal trauma. J Gastroenterol Hepatol 2009;24:757-761.

13 Fabian TC, Croce MA, Stanford GG, Payne LW, Mangiante EC, Voeller GR, Kudsk KA: Factors affecting morbidity following hepatic trauma. A prospective analysis of 482 injuries. Ann Surg 1991;213:540-548.

14 Bajaj JS, Spinelli KS, Dua KS: Postoperative management of noniatrogenic traumatic bile duct injuries: role of endoscopic retrograde cholangiopancreaticography. Surg Endosc 2006;20:974-977.

15 Costamagna G: Benign biliary strictures and leaks; in Ginsberg G, Kochman ML, Norton I, et al (eds): Clinical Gastrointestinal Endoscopy, ed 1. London, Elsevier, pp 695-708. 


\begin{tabular}{l|l}
\hline Case Rep Gastroenterol 2013;7:56-62 \\
\hline DOI: $\underline{10.1159 / 000346570}$ & $\begin{array}{l}\text { ○ 2013 S. Karger AG, Basel } \\
\text { www.karger.com/crg }\end{array}$ \\
\hline
\end{tabular}

Spinn et al.: Successful Endoscopic Therapy of Traumatic Bile Leaks

Table 1. Patients with traumatic bile leak: characteristics, endoscopic interventions, and outcomes

\begin{tabular}{|c|c|c|c|c|c|c|c|c|c|}
\hline $\begin{array}{l}\text { Case } \\
\text { No. }\end{array}$ & $\begin{array}{l}\text { Age, } \\
\text { years/sex }\end{array}$ & Etiology & $\begin{array}{l}\text { Injury } \\
\text { grade }\end{array}$ & $\begin{array}{l}\text { Bile leak } \\
\text { location }\end{array}$ & $\begin{array}{l}\text { Biliary stent, } \\
\text { F/cm }\end{array}$ & $\begin{array}{l}\text { Other biliary } \\
\text { interventions before } \\
\text { ERCPa }\end{array}$ & $\begin{array}{l}\text { ERCP } \\
\text { sessions, } \\
n^{\mathrm{b}}\end{array}$ & $\begin{array}{l}\text { Follow-up, } \\
\text { days }\end{array}$ & Outcome \\
\hline 1 & $50 / \mathrm{M}$ & MVA & IV & CBD & $10 / 7$ & Conservative & 2 & 146 & Success \\
\hline 2 & $55 / \mathrm{M}$ & MVA & IV & Rt. intrahep & $10 / 7$ & Surgery & 2 & 94 & Success \\
\hline 3 & $16 / \mathrm{M}$ & MCA & IV & Rt. intrahep & $8.5 / 9$ & Surgery & 2 & 79 & Success \\
\hline 4 & $25 / \mathrm{M}$ & MVA & IV & Lt. intrahep & $10 / 7$ & Surgery & 2 & 85 & Success \\
\hline 5 & $17 / F$ & MVA & IV & Rt. intrahep & $7 / 5$ & Conservative/IR ${ }^{c}$ & 2 & 65 & Success \\
\hline 6 & $45 / F$ & MVA & III & Rt. intrahep & $8.5 / 15$ & Surgery & 2 & 60 & Success \\
\hline 7 & $40 / \mathrm{M}$ & MVA & IV & Lt. intrahep & $10 / 7$ & Surgery & 2 & 110 & Success \\
\hline 8 & $28 / F$ & MCA & IV & Rt. intrahep & $8.5 / 7$ & Surgery/IRc & 2 & 54 & Success \\
\hline 9 & $43 / \mathrm{M}$ & MCA & IV & Rt. intrahep & $8.5 / 5$ & Surgery & 2 & 80 & Success \\
\hline 10 & $11 / \mathrm{F}$ & MVA & IV & Rt. intrahep & $8.5 / 7$ & Surgery/IRc & 2 & 52 & Success \\
\hline 11 & $37 / F$ & MVA & IV & Rt. intrahep & $8.5 / 5$ & Surgery & 2 & 85 & Success \\
\hline 12 & $61 / \mathrm{M}$ & GSW & $\mathrm{V}$ & Rt. intrahep & $10 / 7$ & Surgery & 2 & 175 & Success \\
\hline 13 & $26 / \mathrm{M}$ & GSW & V & Lt. intrahep & $10 / 7$ & Surgery/IRc & 2 & 58 & Success \\
\hline 14 & $33 / \mathrm{M}$ & GSW & V & Lt. intrahep & $10 / 7$ & Surgery & 2 & 56 & Success \\
\hline
\end{tabular}

Rt. = Right; Lt. = left; intrahep = intrahepatics; IR = interventional radiology.

a Includes interventions pertaining to liver injury.

$b$ Inclusive of the last ERCP session when the biliary stents were removed.

c Includes both CT-guided drainage of biloma and percutaneous drain placement by IR. 